\title{
Varied foci of primary benign schwannoma of the thorax: a case series
}

\author{
Archana Malik', Manju Rajaram ${ }^{1}$, Mahesh Babu Vemuri' ${ }^{1}$, Madhusmita Mohanty Mohapatra ${ }^{1}$, \\ Srinivas $\mathbf{B H}^{2}$, Naren Chandra $\mathbf{V}^{\mathbf{1}}$ \\ ${ }^{1}$ Department of Pulmonary Medicine; ${ }^{2}$ Department of Pathology, Jawaharlal Institute of Postgraduate Medical \\ Education \& Research (JIPMER), Puducherry, India
}

\begin{abstract}
Schwannomas are the most common tumor of peripheral nerves. It comprises 1 to $2 \%$ of total thoracic tumor. Posterior mediastinum is the most common site in thorax. Hereby we are reporting two cases of schwannoma with different sites of origin. The classical presentation of schwannoma is an asymptomatic mass found on chest radiograph. This tumor is usually benign and slow growing. Imaging followed by histopathological examination is key to the diagnosis of this neoplasm. Resection of tumor cure the disease.
\end{abstract}

\section{Introduction}

Schwannomas are the most common tumor of peripheral nerves. It is the most common benign mediastinal neurogenic tumor originating from neural sheath Schwann cell. This tumor commonly occurs on the flexor surfaces of the extremities, neck, mediastinum, retroperitoneum, posterior spinal roots, and cerebellopontine angle [1]. They are generally benign, asymptomatic, slow-growing lesions. Very rarely pleuro-pulmonary schwannomas can be a manifestation of the metastasis from peripheral sites. This tumor compromises of 1 to $2 \%$ of total thoracic tumors [2]. Here we are reporting two cases of schwannoma with varied sites of origin.

Correspondence: Manju Rajaram, Additional professor and Head, Department of Pulmonary Medicine, Jawaharlal Institute of Postgraduate Medical Education \& Research (JIPMER), Puducherry605006, India. E-mail: mail2manju22@gmail.com

Key words: Pulmonary schwannoma; mediastinum; lung mass.

Received for publication: 28 September 2020.

Accepted for publication: 6 March 2021.

${ }^{\circ}$ Copyright: the Author(s), 2021

Licensee PAGEPress, Italy

Monaldi Archives for Chest Disease 2021; 91:1575

doi: 10.4081/monaldi.2021.1575

This article is distributed under the terms of the Creative Commons Attribution Noncommercial License (by-nc 4.0) which permits any noncommercial use, distribution, and reproduction in any medium, provided the original author(s) and source are credited.

\section{Case \#1}

A nineteen-year male presented to Pulmonary Medicine Outpatient Department (OPD) with chief complaints of right sided chest pain for 1 month. His past history is unremarkable. He was a non-smoker and a medical student. There was no family history of neurofibroma or ash leaf macule or neurofibroma were not found on general survey. At the time of presentation his vitals were stable. There were no palpable lymph nodes. Complete blood count and metabolic panel, urinalysis, and electrocardiography were normal. The tuberculin skin test was negative. Chest x-ray was showing mass lesion in right mid and lower zone. Contrast enhanced computed tomography (CECT) thorax was showing non enhancing heterogeneous soft tissue attenuating pleural based mass lesion of size $11 \times 10.9 \times 8.3 \mathrm{~cm}$ along right lower lobe. Medially lesion abutting pericardium, right atrium, and IVC. Laterally abutting lateral chest wall. Differential diagnosis of the pleural based mass considered were solitary fibrous tumor of pleura, mesothelioma and metastatic adenocarcinoma. Ultra sonographic guided biopsy was taken it was showing multiple fragmented core of tissue comprised of lesion with in cell arranged in hypo and hypercellular area (Antony A and Antony B area). With that diagnosis of pulmonary schwannoma was made after multidisciplinary discussion in tumor board clinic. Patient was sent to cardiothoracic vascular surgery (CTVS) department for operative management. Open thoracotomy and resection of tumor was done. The patient had an uneventful postoperative recovery with no adjuvant therapy. Follow up Chest X ray after 6 months showed no residual tumor (Figures 1 to 3 ).

\section{Case \# 2}

A forty-two-year male presented to pulmonary medicine OPD with chief complaints of left sided chest pain for 2 months. There was no history of trauma, no associated comorbidities. He was a smoker with 20 pack years and farmer by occupation. His vitals were stable at the time of presentation. Chest $\mathrm{x}$ ray was taken showing pleural based mass lesion in right upper and midzone with erosion of left second rib. On CECT thorax, well-defined irregular heterogeneously enhancing soft tissue attenuating lesion with few non enhancing areas noted involving left chest wall measuring $7.7 \times 6.2 \times 6.5 \mathrm{~cm}$ with destruction and expansion of left second rib and pressure erosion of anterior aspect of left first rib. Complete blood count and metabolic panel, urinalysis, and electrocardiography were normal. Differential diagnosis considered in this case were solitary fibrous tumor of pleura, Ewing's sarcoma, localized malignant mesothelioma and metastatic adenocarcinoma. CT guided biopsy was taken which showed predominantly 
hyper cellular and a few hypocellular areas. The hypercellular areas show tumor cells which are spindled, palisading with moderate cytoplasm, hyperchromatic nucleus with infrequent mitosis. Immunohistochemistry revealed diffuse positivity for S-100 and negative for CD34 and p53 suggestive of cellular schwannoma. The case was discussed in multidisciplinary tumor board clinic. Patient was referred to CTVS for surgical management and wide local excision of tumor was done along with ribs. The patient had an uneventful postoperative recovery. Follow-up x-ray showed no tumor with segmental collapse of left upper lobe (Figures 4 to 7).

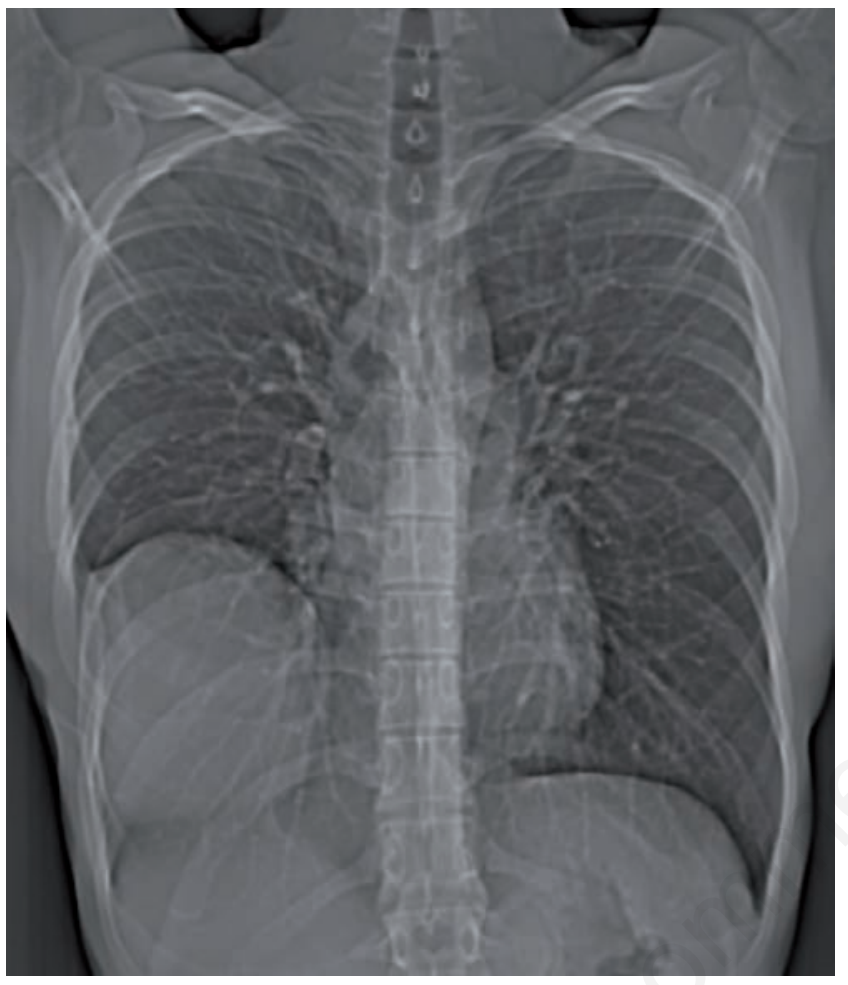

Figure 1. Chest $\mathrm{X}$-ray showing well circumscribed mass lesion in right lower zone.

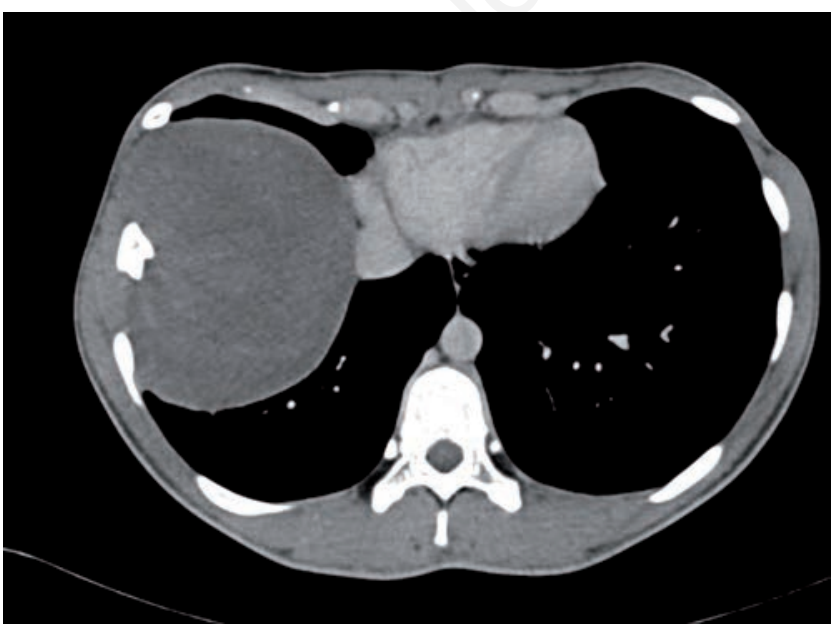

Figure 2. CECT thorax was showing non enhancing heterogeneous soft tissue attenuating pleural based mass lesion of size $11 * 10.9 * 8.3 \mathrm{~cm}$ along right lower lobe.

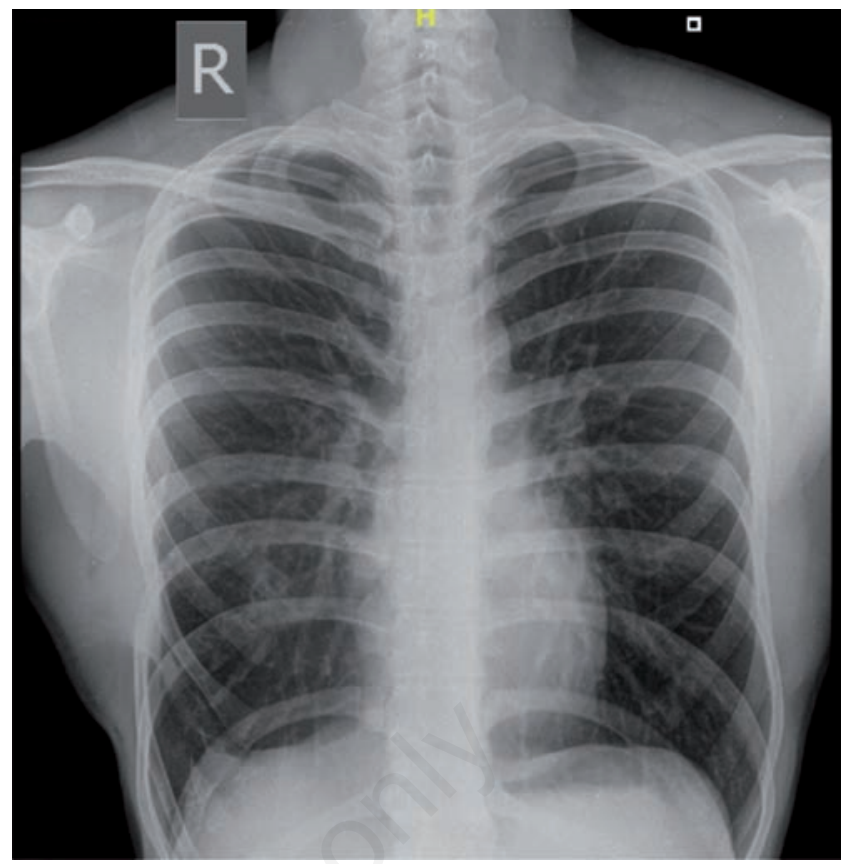

Figure 3. Chest X-ray after excision of the tumor from right lower lobe after 6 months.

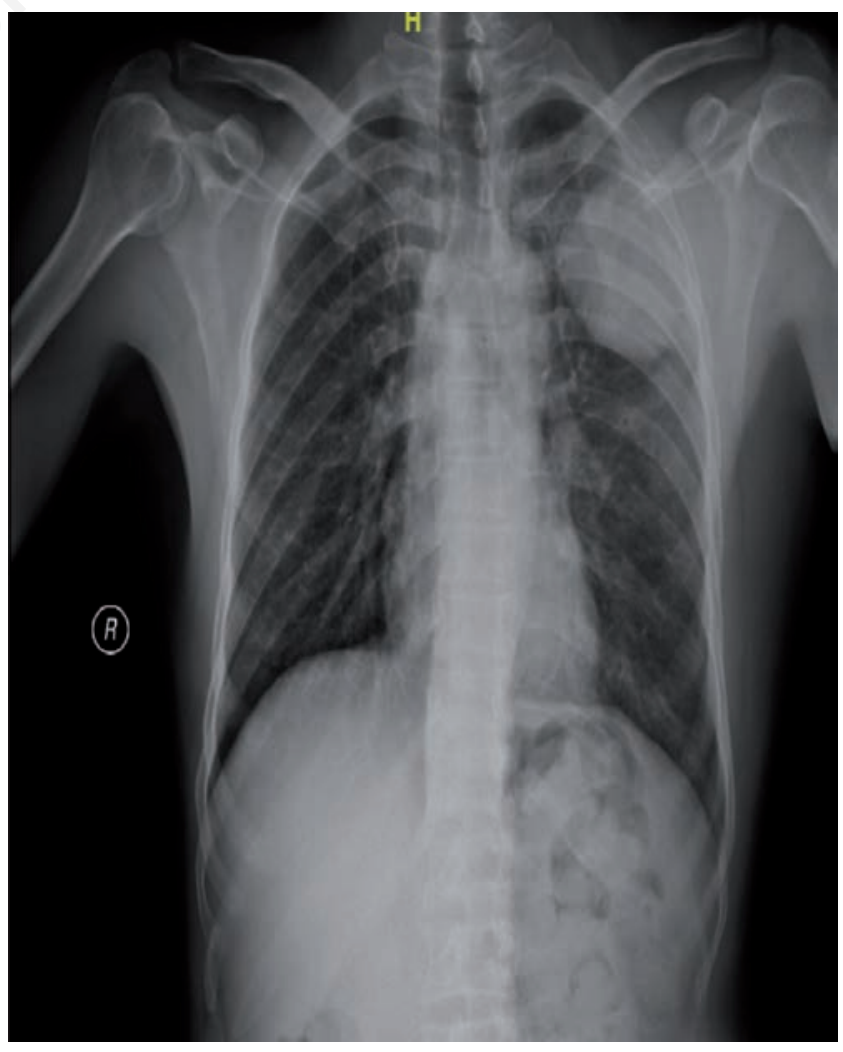

Figure 4. Chest X-ray showing pleural based mass lesion in left upper and mid zone with erosion of left second rib. 


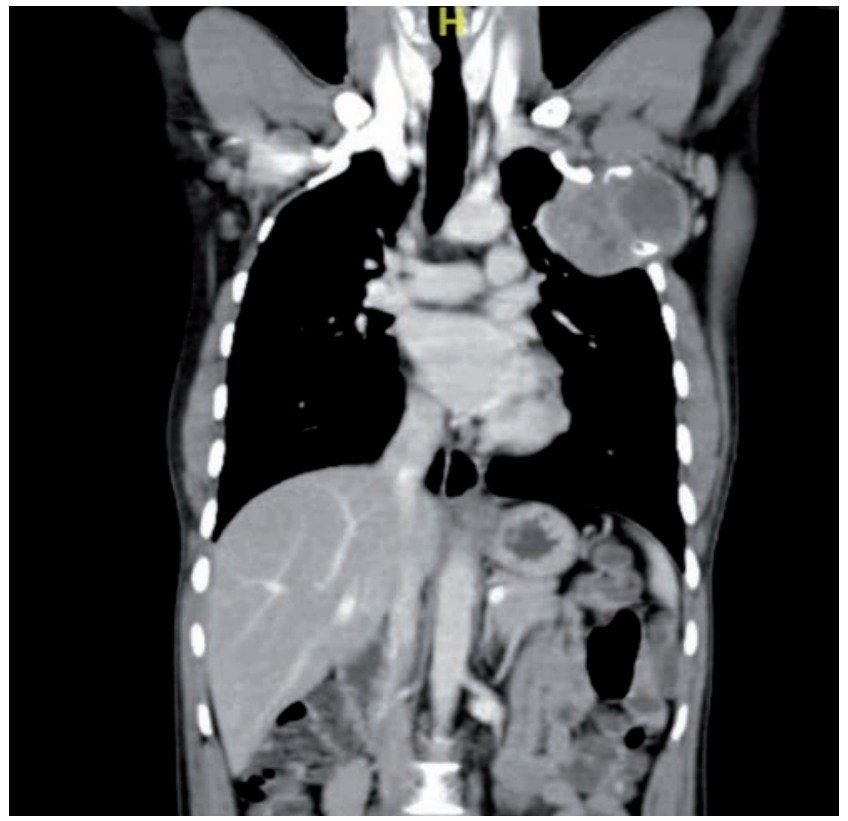

Figure 5. CECT thorax showing well-defined irregular heterogeneously enhancing soft tissue attenuating lesion with few non enhancing areas noted involving left chest wall measuring $7.7 \times 6.2 \times 6.5 \mathrm{~cm}$ with destruction and expansion of left second rib.

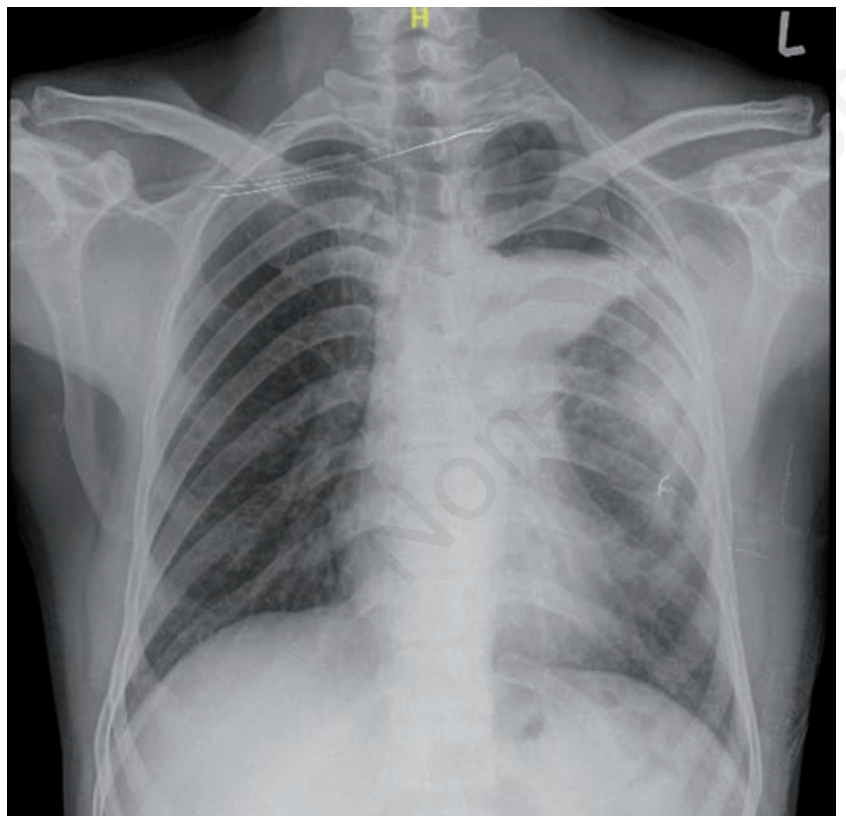

Figure 6. Chest $\mathrm{X}$-ray after excision of tumor.

\section{Discussion}

Neurilemmoma, also termed schwannoma, presents as a well circumscribed and encapsulated mass in the human body and is almost always solitary [3]. Schwannoma is a tumor which arises from the specialized nerve cells which produce myelin called

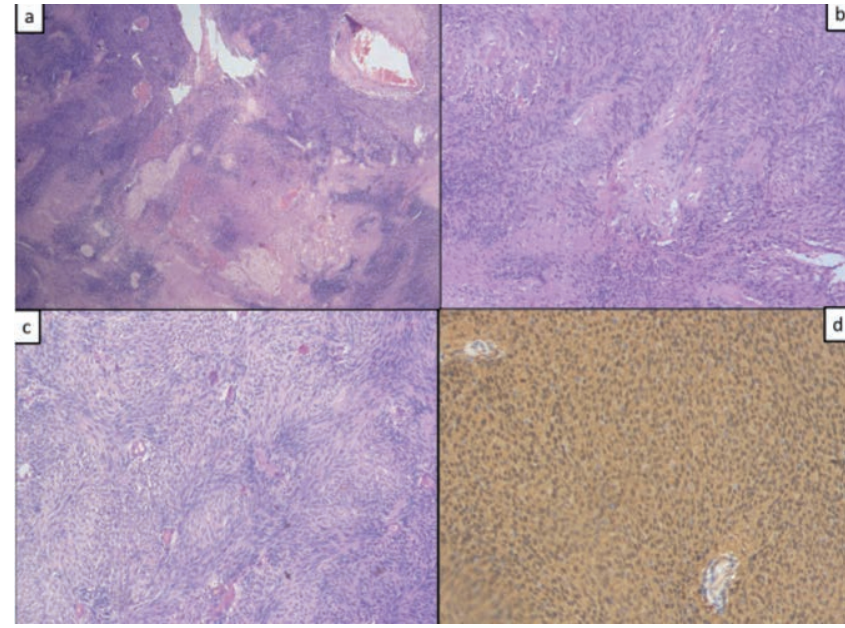

Figure 7. Photomicrographs of histopathological sections. a) Tumor composed of hypercellular and hypocellular areas along with hyalinized blood vessels $(\mathrm{H} \& \mathrm{E}, 40 \mathrm{x})$. b) Sheets of tumor cells with peripheral palisading $(\mathrm{H} \& \mathrm{E}, 100 \mathrm{x})$. c) Cells are in spindle shaped with mild nuclear atypia (H\&E, 200x). d) Immunohistochemistry with $\mathrm{S100}$ shows diffuse strong nuclear positivity (DAB, 200x).

Schwann cells. This kind of tumor is a relatively common mediastinal neurogenic tumor, accounting for about $25.3 \%$ of intrathoracic neurogenic tumors [4]. Posterior mediastinum is the most common site of schwannoma in thorax [5]. They are mostly benign, slowgrowing tumors originating primarily from a spinal nerve root but may involve any thoracic nerve commonly involving intercostal nerves and autonomic nerves, especially sympathetic chain.

According to Otshuka et al., schwannoma affects most commonly males [5]. It is predominant in the third or fourth decades of life [6]. This is a report of 2 male cases with schwannoma and they presented at different ages, one at $2^{\text {nd }}$ decade and other at $4^{\text {th }}$ decade of life. They also stated that $52 \%$ of intra-bronchial and pulmonary schwannoma are symptomatic.[5] On the other hand, most peripheral intrapulmonary schwannoma is asymptomatic [5]. The classical presentation is an asymptomatic mass found on chest radiograph. The major complaints of the patient as described in case series included slight hemoptysis, cough, fever, chest pain and shortness of breath [7]. Both of our patients presented with chest pain.

On radiographic images, peripheral pleural schwannoma appears as a round mass with well-defined margins with minimal contrast enhancement [8]. Malignant pleural schwannomas have been reported in literature but rare [9]. Malignant lesions have been described in patients with neurofibromatosis type 1 and patients with positive history of previous radiation therapy. Malignant lesion can present as pulmonary pleural nodule, pleural effusion, and mass lesion [10]. Benign schwannomas may be large and demonstrate intense heterogeneous FDG activity, mimicking malignancy on 18 FDG PET/CT. Benign and malignant peripheral nerve sheath tumor has similar FDG activity [11]. MRI is also one of the imaging modalities which is used to diagnose schwannoma in which T1 weighted images were isointense with skeletal muscle and T2 images were hyperintense. However, MRI is also not able to differentiate between benign and malignant lesions and this pattern of signal intensity was not specific for neural tumors [12]. So PET CT and MRI were not frequently advised for pulmonary schwannoma. 
Histopathology is essential for diagnosis of benign schwannoma. In histopathology Antoni A and Antoni B areas are revealed in majority of cases. Antoni A represents areas of hypercellularity with Verocay bodies. Antoni B areas of myxoid hypocellularity exhibit degenerating changes (i.e., cyst formation, hemorrhage, calcification, xanthomatous infiltration, and hyalinization). Resection of the tumor is the definitive treatment, and it may be ranging from wedge or sleeve resection, lobectomy or pneumonectomy. This benign lesion rarely recurs after resection [13]. Metastasis to lung from the peripheral tumor has been reported but it's extremely rare [14]. Signs of malignant invasion are absence of capsule, perineural invasion, increased mitotic figures, ill-defined cell borders, areas of hemorrhagic and cystic degeneration [15].

\section{Conclusions}

Schwannoma is an extremely rare neoplasm of thorax. Most of the patient will be asymptomatic. Imaging followed by histopathological examination is key to the diagnosis of this neoplasm. PETCT rarely help to differentiate between malignant and benign tumors. This benign tumor has good prognosis after resection. Hence, schwannoma should be kept as a differential diagnosis when we are dealing with thoracic tumors.

\section{References}

1. Rosai J. Gastrointestinal tract. Stromal tumors. In: Ackerman's surgical pathology. Mosby: 1995. p. 645-7.

2. Athanassiadi K, Kalavrouziotis G, Rondogianni D, et al. Primary chest wall tumors: early and long-term results of surgical treatment. Eur J Cardiothorac Surg 2001;19:589-93.

3. Chrysikos S, Kaponi M, Triantafillidou C, et al. A Rare case of primary intrapulmonary neurilemmoma diagnosed in a $43-$ year-old asymptomatic man with a well-defined intrapulmonary mass. Front Oncol 2018;8:11.
4. Zhu W, Chen D. Vagus nerve schwannoma in the right upper mediastinum. Thor Cancer 2017;8:698-702.

5. Yue Y, Xin H, Xu B-C, et al. Posterior mediastinal neurilemmoma accompanied by intrapulmonary sequestration in the left lower lobe: A case report. Medicine (Baltimore) 2019;98: e16582.

6. Reardon MJ, Conklin LD, Fabre J, et al. Thoracoscopic approach to posterior mediastinal neurogenic tumors in the adult. J Laparoendosc Adv Surg Tech A 1999;9:187-92.

7. Shiao J, Zhu X-H, Shi J-Y, et al. [Primary pulmonary schwannoma: clinical analysis of 7 cases and review of the literature].[Article in Chinese]. Zhonghua Jie He He Hu Xi Za Zhi 2003;26:3-6.

8. Jang JY, Kim JS, Choe JW, et al. A case of giant, benign schwannoma associated with total lung collapse by bloody effusion. Tuberc Respir Dis (Seoul) 2013;75:71-4.

9. Abbas A, Jones H, Kingston GT, Zurek A. Malignant peripheral nerve sheath tumour presenting as a pneumothorax. Br J Radiol 2014;84:e197- 9.

10. Ravikanth RA rare case of primary benign schwannoma of the pleura. Digit Med 36-8.

11. Monson K, Dewey B, Ugorowski M, Bronski S. 18F-FDG PET/CT imaging features of benign schwannomas. J Nuclear Med 2019;60:2053.

12. Hems TEJ, Burge PD, Wilson DJ. The role of magnetic resonance imaging in the management of peripheral nerve tumours. J Hand Surg 1997;22:57-60.

13. Wang W, Cui M, Ma HX, et al. A large schwannoma of the middle mediastinum: A case report and review of the literature. Oncol Lett 2016;11:1719-21.

14. Borghesi A, Bercich L, Michelini S, et al. Pulmonary metastases from malignant epithelioid schwannoma of the arm presenting as fast-growing subsolid nodules: Report of an unusual case. Vol. 6, European journal of radiology open. Eur J Radiol Open 2019;6:307-14.

15. Dellatif AA, Daoud A, Giudice G, et al. Solitary benign primary intra-pulmonary schwannoma of the left lower lobe. J Clin Trials 2019;9:381. 